\title{
What Should We Concern in Reporting Conflict of Interest for Submission of Manuscript in the Psychiatry Investigation?
}

\author{
Jun-Won Hwang \\ Department of Psychiatry, Kangwon National University Hospital, Kangwon University School of Medicine, Chuncheon, Republic of Korea
}

Nowadays, new clause has been added in the Enforcement Rule of the Pharmaceutical Act, often called as the Korean version of the Sunshine Act in U.S., which requires pharmaceutical companies to reveal financial compensation for medical staffs and maintain the documentary evidence for 5 years. ${ }^{1}$ In the Enforcement Rule, self-effort for financial transparency was empathized by legal obligation. In line with this change, the issue of conflict interest should be handled carefully when authors submit the manuscript to the official journal of Korean Neuropsychiatric Association, the Psychiatry Investigation.

In general, the issue of conflict of interest can arise when one's personal interests meet the responsibilities for scientific activities. If conflict of interest may not be handled properly in peer review process, it may lead authors, reviewers, and editorial board members to make decisions which favor their interests at the cost of their responsibilities in the publication. Even when it is not immediately apparent to others, the consequence of conflict of interest seems to be dangerous. In previous study, the conflict of interest in psychiatric clinical trials was associated with a greater likelihood of reporting a drug to be superior to placebo.,

In peer-reviewed medical journals, there can be many types of conflict of interest including not only financial ties but also nonfinancial ones including academic commitments, personal relationships, political or religious beliefs, institutional affiliations, ${ }^{4}$ and role and contribution for the submitted manuscript. ${ }^{5}$ Describing financial ties, the types of financial support for the submitted work (i.e., grant, personal fees and nonfinancial support from government, companies, and private foundation, etc.) should be described properly. In addition, information regarding financial activities beyond the submitted paper and patents and copyrights should be described.

Conflict of interest can be posed by interpersonal relation-

(c) This is an Open Access article distributed under the terms of the Creative Commons Attribution Non-Commercial License (http://creativecommons.org/licenses/by$\mathrm{nc} / 4.0$ ) which permits unrestricted non-commercial use, distribution, and reproduction in any medium, provided the original work is properly cited. ships. Potential influence can be made in review process when some authors' belief challenges reviewers' one or there is academic competition between authors and reviewers. In addition, positive interpersonal relationships with family members and colleagues can bias the review process. Commitment to a particular political party or agenda or religious conviction may also affect the decision of the manuscript. Concerns should be made even when we meet seemingly neutral institutions such as universities, hospitals, research institutes, professional associations, and civic organizations because they may also have potential interests in the results of manuscript. Along with authors' conflict of interest and sources of support for the manuscript, it should be explained whether the authors had access to the data, with an explanation of the extent and nature of the access.

It seems that the consensus of opinion has not been made regarding the report of conflict of interest in the Psychiatry Investigation. We should discuss and elucidate what and what extent we may include for the report of conflict of interest in the author information section.

\section{REFERENCES}

1. South Korea to Introduce Sunshine Laws to Tackle Corruption in Pharmaceutical Industry. Available at: http://koreabizwire.com/southkorea-to-introduce-sunshine-laws-to-tackle-corruption-in-pharmaceutical-industry/86930. Accessed March 7, 2018.

2. Perlis RH, Perlis CS, Wu Y, Hwang C, Joseph M, Nierenberg AA. Industry sponsorship and financial conflict of interest in the reporting of clinical trials in psychiatry. Am J Psychiatry 2005;162:1957-1560.

3. Ahmer S, Arya P, Anderson D, Faruqui R. Conflict of interest in psychiatry. Psychiatr Bull 2005;29:302-304.

4. WAME statement on conflict of interest in peer-reviewed medical journals. Available at: http://www.wame.org/about/conflict-of-interest-in-peer-reviewed-medical. Accessed March 7, 2018.

5. International Committee of Medical Journal Editors. Authors responsibilities-conflicts of interest. Available at: http://www.icmje.org/recommendations/browse/roles-and-responsibilities/author-responsibilities--conflicts-of-interest.html. Accessed March 7, 2018. 